\title{
Antispasmodic effect of hydroalcoholic and flavonoids extracts of Dracocephalum kotschyi on rabbit bladder
}

\author{
Hassan Sadraei $^{*{ }^{\circledR}}$, Seyed Ebrahim Sajjadi ${ }^{(\mathbb{D}}$, Arefe Tarafdar $^{1}$ \\ ${ }^{1}$ Department of Pharmacology and Toxicology, School of Pharmacy and Pharmaceutical Sciences, Isfahan University of Medical Sciences, Isfahan, Iran \\ ${ }^{2}$ Department of Pharmacognosy and, School of Pharmacy and Pharmaceutical Sciences, Isfahan University of Medical Sciences, Isfahan, Iran.
}

\section{A R T I C L E I N F O}

Article Type:

Original Article

Article History:

Received: 25 August 2019

Accepted: 1 December 2019

\section{Keywords:}

Acetylcholine

Bladder

Dracocephalum kotschyi

Electrical field stimulation

$\mathrm{KCl}$

Smooth muscle

\begin{abstract}
A B S T R A C T
Introduction: Dracocephalum kotschyi extract has antispasmodic activities on smooth muscle including ileum, uterus and trachea. The objective of this research was to investigate antispasmodic activity of hydroalcoholic and flavonoids extracts of $D$. kotschyi on rabbit bladder contractions.

Methods: Rabbits were euthanized by carbon dioxide asphyxiation and the whole bladder was dissected out and immersed in the Tyrode's solution. Longitudinal bladder strips were mounted vertically in an organ bath at $37^{\circ} \mathrm{C}$ and gassed continuously with $\mathrm{O}_{2}$. Bladder strips were contracted with acetylcholine $(\mathrm{ACh}), \mathrm{KCl}$, or electrical field stimulation (EFS). Isotonic tension of the tissue was recorded before and after addition of hydroalcoholic or flavonoids rich extracts of D. kotschyi. Nifedipine and propantheline were used as standard drugs.

Results: Standard drug propantheline, prevented bladder phasic contraction induced by ACh $(1 \mu \mathrm{M})$ without affecting $\mathrm{KCl}$ response. On the other hand, cumulative addition of nifedipine attenuated the tonic contractions induced by $\mathrm{KCl}(20 \mathrm{mM})$ on bladder smooth muscle. Hydroalcoholic and flavonoids extracts of $D$. kotschyi at concentration ranges of 10-320 $\mu \mathrm{g} /$ $\mathrm{mL}$ in a concentration dependent way inhibited bladder tonic contraction induced by $\mathrm{KCl}$ $(n=6)$. Both extracts also in a concentration-dependent manner relaxed EFS and ACh-induced contractions (range, $20-1280 \mu \mathrm{g} / \mathrm{mL}$ ) of bladder smooth muscle in vitro. Complete inhibition was achieved with the highest used concentrations of the extracts. The inhibitory effect of the extract was reversible following washing the tissues with fresh Tyrode's solution.

Conclusion: This study clearly demonstrated that $D$. kotschyi extracts were able to prevent contractions induced by $\mathrm{ACh}, \mathrm{KCl}$ or EFS in isolated rabbit bladder. This means that people consuming this medicinal plant may face urinary retention which could be a problem for patients with prostate hypertrophy. On the other hand, this plant might be useful in patients with urinary incontinence. However, its usefulness must be assessed in the controlled clinical trials.
\end{abstract}

Implication for health policy/practice/research/medical education:

This paper provides pharmacological evidence for spasmolytic action of Dracocephalum kotschyi on isolated bladder and therefore it might be useful for treatment of bladder incontinence.

Please cite this paper as: Sadraei H, Sajjadi SE, Tarafdar A. Antispasmodic effect of hydroalcoholic and flavonoids extracts of Dracocephalum kotschyi on rabbit bladder. J Herbmed Pharmacol. 2020;9(2):145-152. doi: 10.34172/jhp.2020.19.

\section{Introduction}

Dracocephalum kotschyi Boiss is a native Iranian flowering plant in the family Lamiaceae (1-3). D. kotschyi (Zaringiah in Persian) is a perennial herbaceous plant with stems growing between 10 and $20 \mathrm{~cm}$ tall (1-3). Although Zaringiah is mainly used as food flavoring herb among Iranian population, nevertheless infusion or decoction of Zaringiah traditionally is used by local people for various ailments (4). Zaringiah is not well documented in the Iranian traditional medicine books and only in a few texts has referred to its anti-inflammatory and anti-rheumatism benefits $(1,2)$.

Zaringiah is enriched in various constituents including essential oils, flavonoids and monoterpene glycosides (5-10). The essential oils and flavonoids components seem to possess the active pharmacologically substances 
(7-11). Geranial, limonene, a-pinene, citral, $\alpha$-terpineol, caryophyllene, terpinyl, Gerania, cyclononadiene, isopinocarveol, terpinene-4-ol, linalool, carveol, myrcene, germacrene-D, etc, accounts for major identified constituents of essential oil (6-8). It has been reported that antinociceptive and anti-inflammatory effects of essential oil is due to action of limonene and a-terpineol (9). Ethanolic extract of D. kotschyi also possess potent antiinflammatory properties (11). Many constituents of the extract also have been identified. Some of these constituents including calycopterin, xanthomicrol, isokaempferide, luteolin, apigenin, luteolin 7-O-beta-D-glucopyranoside, lutcolin 3'-Obeta-D-glucuronide, apigenin 4'-O-beta-Dglucopyranoside, acacetin 7-O-beta-D glucopyranoside, rosmarinic acid are its known components $(10,12)$.

In modern medicine $D$. kotschyi has widely been studied for treatment of diseases other than inflammatory conditions. For instant, D. kotschyi extract has been introduced as one of the components in the drug called Spinal-Z in Iran for treatment of cancer (13). The antitumor activity of D. kotschyi extract has been attributed to its constituent calycopterin and xanthomicrol although anti-proliferative properties for other constituents are also reported (14-16). Immunomodulatory activity is another reported action of $D$. kotschyi extract, which might be associated with its anticancer and anti-inflammatory properties of this plant $(16,17)$.

Modern pharmacological research confirms that $D$. kotschyi has strong antispasmodic activity both in vitro and in vivo (8,18-22). For example, D. kotschyi essential oil and extract has potent antispasmodic activity on isolated ileum $(8,18,20)$ and has been shown to reduce intestinal meal transit in vivo $(19,22)$. In addition, D. kotschyi prevents uterus contraction induced by $\mathrm{KCl}$, oxytocin, acetylcholine (ACh) and neuronal stimulation (21). Furthermore, flavonoids extract of D. kotschyi inhibits tracheal contraction induced by $\mathrm{KCl}$ and $\mathrm{ACh}$ and because of its antispasmodic and anti-inflammatory properties, it was suggested as a suitable herbal remedy for treatment of asthma (23). The antispasmodic of the extract has been suggested to be due to flavonoids constituents such as apigenin and luteolin $(20,23)$. So far there is no report on pharmacological action of $D$. kotschyi on bladder contraction. Therefore, the objective of this research was to investigate spasmolytic effect of $D$. kotschyi extract on isolated bladder smooth muscle contraction in vitro.

\section{Materials and Methods}

Pharmacognosy studies

Aerial parts of Zaringiah were collected from cultivated farm on the base of Shahan Kooh in Feridonshar (IsfahanIran) during flowering season in year 2017. The plant was identified as D. kotschyi by the botanist Mr Asfa from Department of Natural Resources in Isfahan province. A herbarium voucher has been deposited in the School of
Pharmacy and Pharmaceutical Sciences (No. 1519).

The plant materials were dried in shade and grained into fine powder using an electric grinder (Keep, Korea). Hydroalcoholic extract was prepared by maceration technique (24). $300 \mathrm{~g}$ of the plant powder was mixed with $70 \%$ ethanol in order to moisturize the plant material and left at room temperature. Two hours later, the plant materials were packed in a percolator and ethanol (70\%) was added with ratio of 1 to $8(2.4 \mathrm{~L}$ ethanol) making sure that the entire plant materials were soaked in the ethanol. The top of percolator was covered and left for 3 days at room temperature. On the third day, the percolator tap was opened and the extract was collected from bottom of percolator. The process of extraction was repeated thrice. All the collected extracts were added together and concentrated under reduced pressure at $60^{\circ} \mathrm{C}$ with rotary apparatus (Heidolph, Germany). The yield of hydroalcoholic extract was calculated.

The flavonoids extract was prepared from concentrated hydro-alcoholic extract using solvent in solvent fractionations technique (25-27). One hundred grams of hydro-alcoholic fraction of D. kotschyi extract was dissolved in mixture of chloroform and water (1L:1L) and shaken for 20 minutes. This mixture was poured into a decanter and allowed the solvents to be separated. The lower chloroform phase was carefully decanted. The middle phase (semisolid phase) was also removed. Equivalent volume of chloroform was added into the remaining aqueous phase and the process repeated thrice. The chloroform fractions were added together and concentrated with rotary apparatus under $30^{\circ} \mathrm{C}$. The remaining aqueous solvent was further extracted with ethyl acetate solution (1:1 ratio) as described above. Extraction was repeated 5 times and ethyl acetate phase was separated and the solvents were evaporated with rotary apparatus at $50^{\circ} \mathrm{C}$. The percentage yield of the ethyl acetate extract was calculated (W/W).

Assessment of total phenolic contents

Folin-Ciocalteu's phenol reagent test was used for assessment of total phenolic contents of the extracts (28). Gallic acid was used as standard phenol compound. Gallic acid was dissolved in $10 \%$ ethanol as $5 \mathrm{mg} / \mathrm{mL}$ stock solution and further diluted with distilled water in order to prepare stock solutions of 500, 250, 150, 100 and $50 \mu \mathrm{g} / \mathrm{mL}$. In a test tube $20 \mu \mathrm{L}$ of test solution, $100 \mu \mathrm{L}$ of Folin-Ciocalteu's phenol reagent and $300 \mu \mathrm{L}$ of sodium carbonate $(200 \mathrm{mg} / \mathrm{mL})$ were mixed with $1.58 \mathrm{ml}$ distilled water and stored at dark. After 2 hours incubation at room temperature, standard cuvette was filled with this solution and light absorption was read at $765 \mathrm{~nm}$ wavelength with a light spectrophotometer (Jenway 5105, UV/V, England). Calibration curve for gallic acid was drawn by plotting each concentration of gallic acid against its light absorption and straight line was fitted. The extracts samples were 
prepared as with gallic acid and after reading their light absorption at $765 \mathrm{~nm}$ wavelength, concentration of total phenolic content was calculated from the standard graph.

Pharmacological studies

Drugs and solutions

Tyrode's solution was made in distilled water with the following composition (mM): $\mathrm{NaCl}$ (136.6), $\mathrm{NaHCO}_{3}$ (11.9), glucose (5.55), $\mathrm{KCl}$ (2.68), $\mathrm{CaCl}_{2}$ (1.8), $\mathrm{MgCl}_{2}$ (1.05) and $\mathrm{NaH}_{2} \mathrm{PO}_{4}$ (0.42). Hydroalcoholic and flavonoids extracts were made up in dimethylsulphoxide (DMSO) as $80 \mathrm{mg} / \mathrm{mL}$ and $40 \mathrm{mg} / \mathrm{mL}$ stock solutions, respectively. Further dilution was made in 50\% DMSO. Nifedipine was made up as $2 \mathrm{mg} / \mathrm{mL}$ stock solution in DMSO. Further dilution was made in DMSO or distilled water as appropriate. Propantheline was made up as 4.5 $\mu \mathrm{g} / \mathrm{mL}$ stock solution in distilled water. Further dilution was prepared in distilled water. $\mathrm{KCl}$ and $\mathrm{ACh}$ were prepared as $2 \mathrm{M}$ and $100 \mu \mathrm{M}$ stock solutions in distilled water, respectively.

\section{Antispasmodic investigation}

Local rabbits bred in open field farm in Isfahan, was located in the School of Pharmacy and Pharmaceutical Sciences animal house at room temperature with full access to food and water. On each morning, a rabbit was placed in glass chamber $(25 \times 40 \times 30 \mathrm{~cm})$ and euthanized by carbon dioxide asphyxiation. Then, the abdominal cavity was opened and bladder was identified and carefully dissected out and immersed in oxygenated Tyrode's solution. Isolated rabbit bladder was cut in four separate longitudinal strips. One end of strip was tied into a hook and placed in an organ bath (Palmer, England) at $37^{\circ} \mathrm{C}$ and gassed continuously with oxygen. Other end of the tissue was tied into isotonic transducer (Harvard) and held under $1 \mathrm{~g}$ tension. Bladder contractions were recorded on Harvard Universal Oscillograph (England). Following calibration of Oscillograph, the tissue was washed several times and allowed to relax into a stable basal tension. Initially, the tissue response to a single concentration of $\mathrm{ACh}(1 \mu \mathrm{M})$ was determined. Only the tissues with appropriate response to ACh were used in this research.

Smooth muscle contractions of rabbit bladder strips were induced either by addition of $\mathrm{KCl}(20 \mathrm{mM})$, ACh $(1 \mu \mathrm{M})$ or electrical field stimulation (EFS, $6 \mathrm{~V}, 50 \mathrm{~Hz}$ and 1 second duration). $\mathrm{KCl}$ was added directly into the organ bath and contraction recording continued at least for 15 minutes before drugs (nifedipine, propantheline) or extracts (hydro-alcoholic, flavonoids) were added in a cumulative manner. Drugs were added at 5-minute intervals while extract was added at 12-minute intervals. Effects of drugs and extracts on ACh and EFS response were studied in a non-cumulative manner. Each drug or extract concentration was at least 5 minutes in contact with the tissue before its effect was evaluated. Full concentration response curves were constructed in each case. In the parallel time-matched control tissues effects of equivalent volume of extract vehicle were examined.

Statistics and data analysis

Bladder contractions were assessed as maximum amplitude of induced contraction from the baseline and expressed as percentage of initial response prior to addition of the test drug. Data are presented as mean \pm standard error of mean (SEM) for each group of results. For statistical analysis, one-way analysis of variance (ANOVA) or unpaired Student's $t$ test were used for comparison with corresponding time matched vehicle treated control group. $P$ value less than 0.05 was considered statistically significant.

\section{Results}

Pharmacognosy studies

Hydro-alcoholic extract of D. kotschyi had a dark green color. The yield of the hydro-alcoholic extract was calculated 21\% (W/W). Total phenolic contents of the extracts are summarized in Table 1 . The most phenolic contents were found in the ethyl acetate extract and therefore recognized as flavonoids rich extract. The yield of flavonoids extract from the hydro-alcoholic extract was calculated as $13.9 \%(\mathrm{~W} / \mathrm{W})$. This means that flavonoids extract accounts for $2.9 \%$ of the dried plant materials.

\section{Pharmacological studies}

Isolated strips of rabbit bladder suspended in the organ bath gradually relaxed into a relatively stable tension and exhibited spontaneous contractile activities which gradually subsided down over the time. Addition of $\mathrm{KCl}$ (20mM bath concentration) produced a tonic sustained contraction which was maintained over the course of studies. Addition of ACh induced a single phasic contraction, reaching to its peak within 30 seconds contact time. Following washing the tissue with fresh Tyrode's solution it relaxed back to the baseline. Application of EFS produced a sharp contraction which quickly returned toward the baseline following cessation of stimulation.

Propantheline $(60 \mathrm{pg} / \mathrm{mL}$ to $8 \mathrm{ng} / \mathrm{mL})$ in a concentration dependent manner inhibited phasic contraction induced by $\mathrm{ACh} \quad\left(\mathrm{IC}_{50}=0.5 \pm 0.16 \mathrm{ng} / \mathrm{mL}\right)$ without affecting

Table 1. Total phenolic contents of the Dracocephalum kotschyi extracts

\begin{tabular}{ll}
\hline \% Phenolic contents $(\mathbf{n}=\mathbf{3})$ & \\
\hline Hydro-alcoholic extract & $1.27 \pm 0.09$ \\
Ethyl acetate extract & $2.4 \pm 0.11$ \\
Chloroform extract & $0.06 \pm 0.006$ \\
Remained aqueous extract & $0.69 \pm 0.09$ \\
\hline
\end{tabular}

Folin-Ciocalteu's phenol reagent test was used for assessment of total phenolic contents and gallic acid was used as standard phenol compound. Light absorption was read at $765 \mathrm{~nm}$ wavelength. 
$\mathrm{KCl}$ response (Figure 1). Higher concentrations of propantheline (40 ng/mL \& $80 \mathrm{ng} / \mathrm{mL}$ ) also had no effect on $\mathrm{KCl}$ induced contraction of rabbit bladder (Figure 2). Propantheline at concentrations which inhibited ACh response caused no significant inhibitory effect on EFS response. However, at higher concentrations (40 ng/ $\mathrm{mL}$ and $80 \mathrm{ng} / \mathrm{mL}$ ) partially but significantly reduced EFS contractile response of rabbit isolated bladder strip (Figure 2).

Unlike, propantheline, nifedipine $(100 \mathrm{pg} / \mathrm{mL}$ to 1.6 $\mu \mathrm{g} / \mathrm{mL}$ bath concentrations) inhibited $\mathrm{KCl}$ induced contractions in rabbit bladder strips with $\mathrm{IC}_{50}$ value of $37 \pm 10.3 \mathrm{ng} / \mathrm{mL}$ (Figure 3). Nifedipine at similar concentration ranges also inhibited $\mathrm{ACh}$ induced responses. However, complete inhibition was not achieved and at the highest bath concentration used still $12 \%$ of initial contraction remained (Figure 3). Nifedipine also inhibited bladder response to EFS but complete inhibition was not achieved. The inhibitory concentration was seen at $25 \mathrm{ng} / \mathrm{mL}$ bath concentration and maximum inhibition was seen with $6.4 \mu \mathrm{g} / \mathrm{mL}$ bath concentration. Increasing the concentration to $25 \mu \mathrm{g} / \mathrm{mL}$ had no further inhibitory effect and still $8 \%$ of initial response remained (Figure 3). The $\mathrm{IC}_{50}$ values can be seen in Table 2 .

Hydroalcoholic and flavonoids extracts of D. kotschyi in a concentration dependent manner inhibited $\mathrm{KCl}$ induced tonic contraction in rabbit bladder strips. Initial inhibitory effect was observed with $10 \mu \mathrm{g} / \mathrm{mL}$ extracts in the bath and complete inhibition was achieved with 320 $\mu \mathrm{g} / \mathrm{mL}$ bath concentrations (Figure 4 ). The $\mathrm{IC}_{50}$ values are compared in Table 2. Following washing the tissue with fresh Tyrode's solution, contractile response of bladder strip to $\mathrm{KCl}$ gradually was restored. Addition of equal volume of extract vehicle (DMSO) only at the highest used

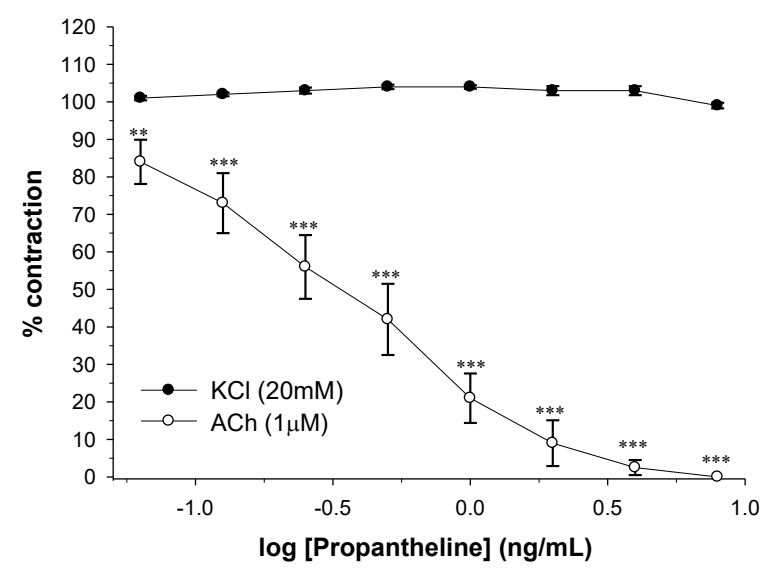

Figure 1. Effect of propantheline on acetylcholine (ACh) and $\mathrm{KCl}$ induced contractions in rabbit isolated bladder strips. Propantheline was added into bath with 2 fold increment in concentration. Data are presented as mean $\pm \operatorname{SEM}(n=6)$. Stars shows statistically significant changes in the ACh response $\left({ }^{* *} P<0.01\right.$, ${ }^{* * *} P<0.001$, Student's $t$ test). There are no statistically significant changes in the $\mathrm{KCl}$ response over the course of study (ANOVA).

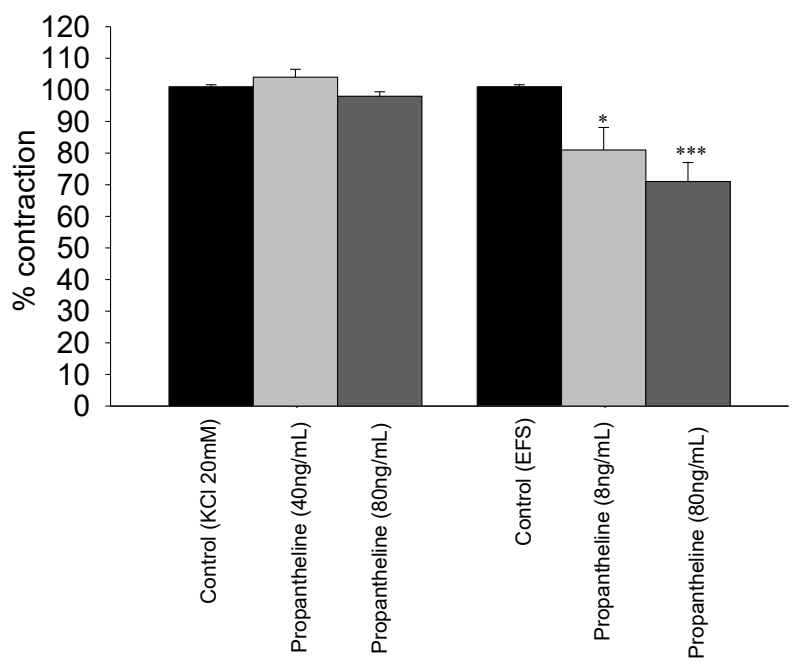

Figure 2. Effects of high concentrations of propantheline on $\mathrm{KCl}(n=4)$ and electrical field stimulation (EFS, $n=6$ ) responses of rabbit isolated bladder strips. Data are presented as mean \pm SEM. Asterisk symbols show statistically significant inhibition in comparison with the initial control group ( ${ }^{\star *} P<0.01,{ }^{* * *} P<0.001$, Student's $t$ test).

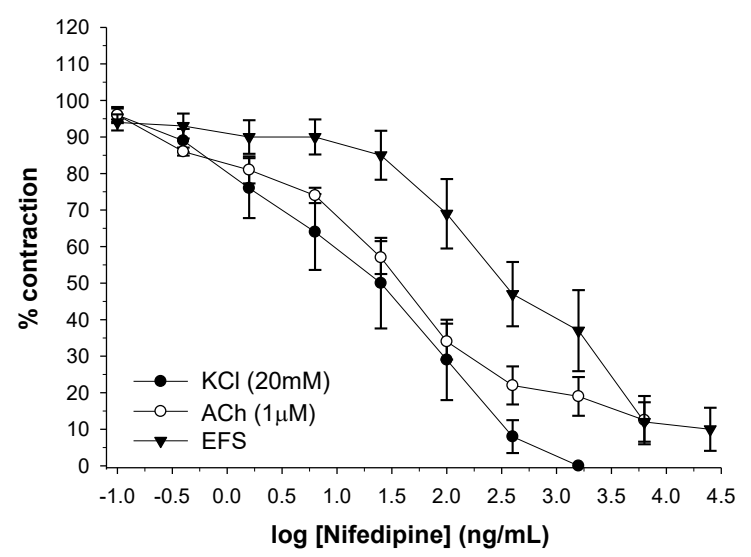

Figure 3. Effect nifedipine on $\mathrm{KCl}$, acetylcholine ( $\mathrm{ACh}$ ) and electrical field stimulation (EFS) induced contractions on rabbit isolated bladder strips. Results are expressed as \% of initial contraction prior to addition of nifedipine. Data are presented as mean \pm SEM $(n=6)$. Nifedipine was $5 \mathrm{~min}$ in contact with the tissue before its effect was evaluated. Inhibition of contraction in all cases was statistically significant (ANOVA, $P<0.001$ ).

concentration slightly reduced $\mathrm{KCl}$ response (Figure 4). Addition of D. kotschyi extracts into the organ bath at 5 minutes intervals gradually attenuated phasic contraction induced by ACh. Inhibitory effect of hydro-alcoholic extract was seen with $160 \mu \mathrm{g} / \mathrm{mL}$ bath concentration and ACh response was removed with $1.28 \mathrm{mg} / \mathrm{mL}$ extract in the bath (Figure 5). The inhibitory effect of flavonoids extract was started with $80 \mu \mathrm{g} / \mathrm{mL}$ extract in the bath and at bath concentration of $640 \mu \mathrm{g} / \mathrm{mL}$ almost abolished (Figure 5). The $\mathrm{IC}_{50}$ values are presented in Table 2 . The inhibitory effects of the extracts on ACh responses were reversible following washing the tissues with fresh Tyrode's solution. 
Table 2. Comparison of inhibitory concentrations causing $50 \%$ of maximum response $\left(\mathrm{IC}_{50}\right.$ value) of nifedipine and Dracocephalum kotschyi extracts

\begin{tabular}{lccc}
\hline & \multicolumn{3}{c}{ IC $_{50}$ values } \\
\cline { 2 - 4 } & $\mathrm{KCl}(\mathbf{2 0 \mathrm { mM } )}$ & ACh $(1 \mu \mathrm{M})$ & EFS \\
\hline Nifedipine & $37 \pm 10.3 \mathrm{ng} / \mathrm{mL}$ & $30 \pm 6 \mathrm{ng} / \mathrm{mL}$ & $0.4 \pm 0.18 \mu \mathrm{g} / \mathrm{mL}$ \\
Hydro-alcoholic & $53 \pm 6 \mu \mathrm{g} / \mathrm{mL}$ & $243 \pm 38 \mu \mathrm{g} / \mathrm{mL}$ & $170 \pm 15 \mu \mathrm{g} / \mathrm{mL}$ \\
extract & & & \\
$\begin{array}{l}\text { Flavonoids } \\
\text { extract }\end{array}$ & $102 \pm 9 \mu \mathrm{g} / \mathrm{mL}$ & $190 \pm 58 \mu \mathrm{g} / \mathrm{mL}$ & $105 \pm 27 \mu \mathrm{g} / \mathrm{mL}$ \\
\hline
\end{tabular}

In the control group treated with vehicle (DMSO), ACh response was slightly potentiated (Figure 5).

Both hydro-alcoholic and flavonoids extracts of $D$. kotschyi in a concentration dependent way reduced rabbit bladder strips responses to EFS. First sign of inhibition was observed with $10 \mu \mathrm{g} / \mathrm{mL}$ extract in the bath. However, complete inhibition was not achieved and with bath concentration of $640 \mu \mathrm{g} / \mathrm{mL}$ still $15 \%$ and $7 \%$ of initial response remained respectively (Figure 6). The inhibitory effect of the extracts on EFS response was reversible following washing the tissue. The $\mathrm{IC}_{50}$ values are presented in Table 2 for comparison with $\mathrm{KCl}$ and $\mathrm{ACh}$ responses. There was no statistically significant change in the tissue response in the time matched control tissue treated with the vehicle (DMSO) (Figure 6).

\section{Discussion}

Bladder is a part of lower urinary tract and its function is storage and excretion of urine. The bladder is a hollow sac, the wall of which mainly consists of smooth muscles covered by several impermeable membrane layers (29-32). The bladder body comprise of detrusor

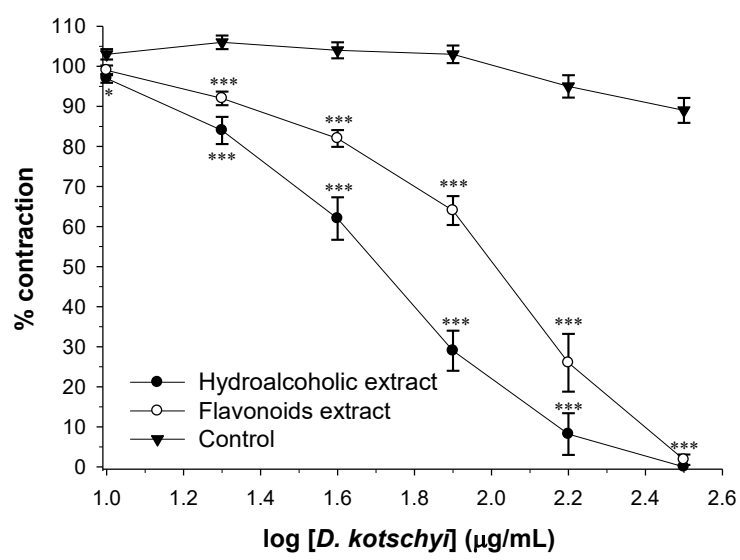

Figure 4. Inhibitory effect of Dracocephalum kotschyi extracts on $\mathrm{KCl}$ induced contraction in rabbit isolated bladder strips. Results are expressed as percentage of initial response prior to addition of the extracts. Data are presented as mean \pm SEM $(n=6)$. Asterisk symbols show statistically significant difference in comparison with the control group treated with the vehicle $\left({ }^{*} P<0.05,{ }^{* *} P<0.001\right.$, Student's $t$ test). The highest used concentration of vehicle (DMSO, $1.5 \%$ ) slightly but significantly attenuated $\mathrm{KCl}$ induced response (ANOVA, $P<0.001$ ). and trigonal smooth muscles. The detrusor is innervated by parasympathetic nerves system and forms major muscular wall of the bladder. Detrusor muscle relaxes during bladder filling and contracts during micturition (33). The trigone structurally and functionally is different from detrusor and mainly innervated by sympathetic nerves system (34). Changes in the detrusor activity may result in urinary problem including incontinence or urine retention (35). The smooth muscle cells layers are oriented

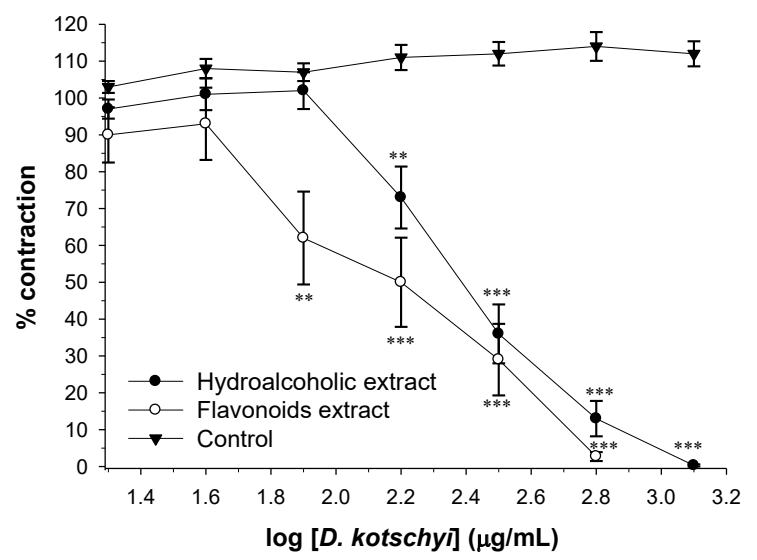

Figure 5. Inhibitory effect of Dracocephalum kotschyi extracts on acetylcholine ( $\mathrm{ACh}$ ) induced contraction in rabbit isolated bladder strips. Results are expressed as percentage of initial response prior to addition of extracts. Data are presented as mean \pm SEM $(n=6)$. Stars show statistically significant difference in comparison with the control group treated with the vehicle $\left({ }^{* *} P<0.01\right.$, ${ }^{* * *} P<0.001$, Student's $t$ test). There was no reduction in the tissue response in the control group treated with equivalent volume of vehicle (DMSO). Maximum used concentration of DMSO was $0.8 \%$

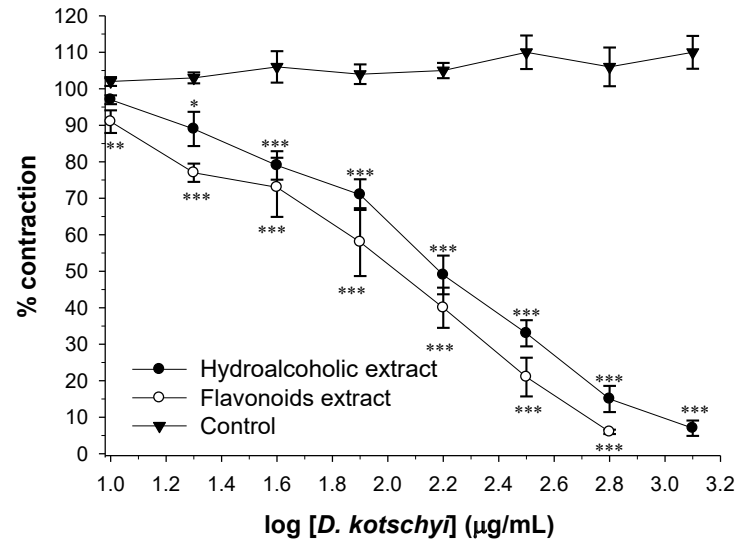

Figure 6. Inhibitory effect of Dracocephalum kotschyi extracts on electrical field stimulation (EFS) induced contraction in rabbit isolated bladder strips. Results are expressed as percentage of initial response prior to addition of extracts. Data are presented as mean \pm SEM $(n=6)$. Stars show statistically significant difference in comparison with the control group treated with the vehicle $\left({ }^{*} P<0.05\right.$, ${ }^{* *} P<0.01,{ }^{* * *} P<0.001$, Student's $t$ test). There was no reduction in the tissue response in the control group treated with equivalent volume of vehicle (DMSO). Maximum used concentration of DMSO was $1.6 \%$. 
both longitudinally and circularly (29). Although most smooth muscles have common pharmacologic properties nevertheless, significant variation has been seen in their responses. Detrusor smooth muscles are long, spindleshaped cells like other typical smooth muscle cells (29-34). However, they have capability to relax to several hundred micrometers long $(33,34)$. This property was responsible for the relaxation of bladder strips in the organ bath. This elongation allows urine storage during filling period. Micturition is due to synchronized and fast muscle contraction which is due to parasympathetic activity initiated by stretch reflex from bladder wall $(35,36)$. Acetylcholine released from parasympathetic neurons act on muscarinic receptors. Activation of muscarinic receptors increase phospholipase- $\mathrm{C}$ activity, production of inositol triphosphate $\left(\mathrm{IP}_{3}\right)$, release of intracellular $\mathrm{Ca}^{2+}$ ions, and smooth muscle contractions. In addition to autonomic nervous system, there are substantial reports that non-adrenergic non-cholinergic (NANC) neurotransmitters including ATP, nitric oxide, vasoactive intestinal peptide, neurokinines and prostaglandins also have functional roles in the bladder contraction and relaxation process $(34,37)$. Furthermore, it has been reported that a minority of muscle fibers generates spontaneous action potentials in response to bladder stretches (36) which could explain spontaneous activity observed in the bladder strips suspended under $1 \mathrm{~g}$ tension in the organ bath. The main objective of this research was to investigate effect of $D$. kotschyi extract on isolated strips of detrusor smooth muscles. For this purpose each tissue was initially challenged with ACh. Bladder strips comprised of detrusor smooth muscles quickly responded to ACh with fast and sharp contraction. Smooth muscle contraction is initiated by an increase in the cytoplasmic $\mathrm{Ca}^{2+}$ ions concentration $(38,39)$. ACh mainly acts on $\mathrm{M}_{2}$ and $\mathrm{M}_{3}$ subtypes receptors in the detrusor smooth muscle $(40,41)$. These receptors are G-protein couple receptors associated with phospholipase $\mathrm{C}$ enzyme system and generation of intracellular second messenger $\mathrm{IP}_{3}$ (42). $\mathrm{IP}_{3}$ causes release of $\mathrm{Ca}^{2+}$ ions from intracellular stores (42). Like other smooth muscles, increase in free cytoplasmic $\mathrm{Ca}^{2+}$ ions activates myosin light chain kinase. Phosphorylation of myosin light chain, results in shortening of myofilaments and thus force is generated (43, 44). In the case of $\mathrm{KCl}$ induced contraction, enhancement of intracellular $\mathrm{Ca}^{2+}$ ion concentration is mainly due to $\mathrm{Ca}^{2+}$ influx through L-type calcium channels (45-47). Nifedipine, a selective blocker of L-type $\mathrm{Ca}^{2+}$ channels, (48) by blocking $\mathrm{Ca}^{2+}$ entry into the cell abolished $\mathrm{KCl}$ induced contraction of bladder strips. On the other hand, propantheline, a muscarinic receptor antagonist, did not affect $\mathrm{KCl}$ induced response but totally removed $\mathrm{ACh}$ induced contraction in the bladder strips suspended in the organ bath. This is because propantheline antagonizes muscarinic receptors on the cell membrane $(49,50)$.
Nifedipine partially inhibited ACh response and this may indicate that following release of $\mathrm{Ca}^{2+}$ from sarcoplasmic reticulum, voltage gated $\mathrm{Ca}^{2+}$ channels are activated via $\mathrm{Ca}^{2+}$ induced calcium channel activation (46). Application of EFS stimulates all the neurons networks in the bladder wall and therefore directly and indirectly stimulates smooth contraction. The nature of contraction depends of contribution of types of neurotransmitters released during stimulation periods. Partial inhibition of EFS response by propantheline indicates that cholinergic transmission has partial role in the process of EFS stimulation. This is consistent with other reports which investigated effect of muscarinic antagonist on bladder EFS stimulation (51). This shows that NANC neurotransmission has major role in contraction induced by application of EFS on bladder smooth muscles. Partial inhibition of EFS response by nifedipine indicates that activation of voltage gated $\mathrm{Ca}^{2+}$ channels has major contribution in the EFS induced contraction.

Both hydroalcoholic and flavonoids extracts of $D$. kotschyi inhibited bladder contraction induced by $\mathrm{KCl}$, $\mathrm{ACh}$ and EFS in bladder strip suspended in the organ bath. These findings indicate that active substance in the extracts may have affected the final stage of contraction process. However, another possibility is existence of several active ingredients in the extract with different mechanism of action which of course needs to be investigated. Comparison of total and flavonoids rich extracts also indicates that $D$. kotschyi extract is enrich in active components. For instance, it can be seen that total hydro-alcoholic extract is more effective than flavonoids rich extract in inhibiting $\mathrm{KCl}$ induced responses (see Figure 4). This shows existence of active ingredients in the total extract which probably are not flavonoids and possibly dissolved in the chloroform phase and needs proper investigation. Among the flavonoids identified in the D. kotschyi extract apigenin and luteolin have antispasmodic activity on isolated ileum and uterus smooth muscles $(20,23,52)$.

These findings confirm spasmolytic action of D. kotschyi extract on isolated rabbit bladder and furthermore indicate that active flavonoids exist that have substantial roles in inhibiting bladder contraction. Although D. kotschyi is used as food flavoring agent and herbal medicine, our results indicate that potent pharmacologically active compounds exist in the plant extracts.

Inhibition of bladder contraction means that over consumption might result in urinary retention. Urinary retention is major problem with muscarinic antagonist and contraindicated for patients with prostate hypertrophy. As D. kotschyi extract is more potent than propantheline, it should be warned that it may aggravate micturition difficulty in people with prostate hypertrophy. On the other hand, in patients with bladder incontinence, $D$. kotschyi could inhibit uncontrolled spasm of bladder and 
could have beneficiary effect for these patients. However, its effectiveness must be determined in clinical situation.

\section{Conclusion}

This study confirms spasmolytic activity of D. kotschyi extract on isolated rabbit bladder in vitro. This means that although $D$. kotschyi extract may have beneficiary effect for control of bladdery incontinence due to involuntary bladder spasm. However, it should be avoided in patients with prostate hypertrophy.

\section{Acknowledgement}

This project was part of Pharm D. thesis of Arefe Tarafdar as Pharm D. student at Isfahan University of Medical Sciences.

\section{Authors' contributions}

HS was project manager and was responsible for writing the paper. SES was supervised extract preparation. HS supervised the pharmacological studies. AT was responsible for the experimental work and analysis of data. All authors approved the final manuscript.

\section{Conflict of interests}

The authors declare no conflict of interests.

\section{Ethical considerations}

Animal care and experiments were performed in accordance with the guidelines for the care and use of laboratory animal of the Isfahan University of Medical Sciences. The project was confirmed by the ethical committee of the university (IR.MUI.RESEARCH. REC.1398.047).

\section{Funding/Support}

This research project financially was supported by Research Department of Isfahan University of Medical Sciences (Project No: 398038).

\section{References}

1. Rechinger KH. Dracocephalum. In: Iranica F, Rechinger $\mathrm{KH}$, ed. Akademische Druck-U. Vol. 150. Verlagsanstalt Graz, Austria; 1986. p. 218-31.

2. Naghibi F, Mosaddegh M, Mohammadi Motamed M, Ghorbani A. Labiatae family in folk medicine in Iran: from ethnobotany to pharmacology. Iran J Pharm Res. 2010;4(2):63-79. doi: 10.22037/ijpr.2010.619.

3. Ghahreman A. Flore de Iranica en couleur naturelle. Tehran: Tehran University Publication; 1987. p. 432.

4. Heydari P, Yavari M, Adibi P, Asghari G, Ghanadian SM, Dida GO, et al. Medicinal properties and active constituents of Dracocephalum kotschyi and its significance in Iran: a systematic review. Evid Based Complement Alternat Med. 2019;2019:9465309. doi: 10.1155/2019/9465309.

5. Saeidnia S, Gohari AR, Uchiyama N, Ito M, Honda G, Kiuchi F. Two new monoterpene glycosides and trypanocidal terpenoids from Dracocephalum kotschyi. Chem Pharm Bull
(Tokyo). 2004;52(10):1249-50. doi: 10.1248/cpb.52.1249.

6. Yaghmai MS, Taffazoli R. The essential oil of Dracocephalum kotschyi Boiss. Flavour Fragr J. 1988;3(1):33-6. doi: 10.1002/ ffj.2730030107.

7. Saeidnia S, Gohari AR, Hadjiakhoondi A, Shafiee A. Bioactive compounds of the volatile oil of Dracocephalum kotschyi. Z Naturforsch C J Biosci. 2007;62(11-12):793-6. doi: 10.1515/znc-2007-11-1203.

8. Sadraei H, Asghari G, Kasiri F. Comparison of antispasmodic effects of Dracocephalum kotschyi essential oil, limonene and alpha-terpineol. Res Pharm Sci. 2015;10(2):109-16.

9. Golshani S, Karamkhani F, Monsef-Esfehani HR, Abdollahi M. Antinociceptive effects of the essential oil of Dracocephalum kotschyi in the mouse writhing test. J Pharm Pharm Sci. 2004;7(1):76-9.

10. Gohari AR, Saeidnia S, Matsuo K, Uchiyama N, Yagura T, Ito M, et al. Flavonoid constituents of Dracocephalum kotschyi growing in Iran and their trypanocidal activity. Nat Med. 2003;57(6):250-2.

11. Sadraei H, Asghari G, Khanabadi M, Minaiyan M. Antiinflammatory effect of apigenin and hydroalcoholic extract of Dracocephalum kotschyi on acetic acid-induced colitis in rats. Res Pharm Sci. 2017;12(4):322-9. doi: 10.4103/17355362.212050.

12. Fattahi M, Nazeri V, Torras-Claveria L, Sefidkon F, Cusido $\mathrm{RM}$, Zamani $\mathrm{Z}$, et al. Identification and quantification of leaf surface flavonoids in wild-growing populations of Dracocephalum kotschyi by LC-DAD-ESI-MS. Food Chem. 2013;141(1):139-46. doi: 10.1016/j.foodchem.2013.03.019.

13. Mashak B, Hoseinzadeh M, Ehsanpour A, Ghanbaran AR, Vakili M. Evaluation of treatment response and side effects of spinal-Z in patients with metastatic gastroesophageal adenocarcinoma: a double-blind randomized controlled trial. Jundishapur J Chronic Dis Care. 2017;6(3):e57870. doi: $10.5812 / \mathrm{jjcdc} .57870$.

14. Jahaniani F, Ebrahimi SA, Rahbar-Roshandel N, Mahmoudian M. Xanthomicrol is the main cytotoxic component of Dracocephalum kotschyii and a potential anticancer agent. Phytochemistry. 2005;66(13):1581-92. doi: 10.1016/j.phytochem.2005.04.035.

15. Talari M, Seydi E, Salimi A, Mohsenifar Z, Kamalinejad M, Pourahmad J. Dracocephalum: novel anticancer plant acting on liver cancer cell mitochondria. Biomed Res Int. 2014;2014:892170. doi: 10.1155/2014/892170.

16. Faham N, Javidnia K, Bahmani M, Amirghofran Z. Calycopterin, an immunoinhibitory compound from the extract of Dracocephalum kotschyi. Phytother Res. 2008;22(9):1154-8. doi: 10.1002/ptr.2382.

17. Amirghofran Z, Azadbakht M, Karimi MH. Evaluation of the immunomodulatory effects of five herbal plants. J Ethnopharmacol. 2000;72(1-2):167-72. doi: 10.1016/s03788741(00)00234-8.

18. Sadraei H, Asghari G, Kasiri F. Antispasmodic effect of Dracocephalum kotschyi hydroalcoholic extract on rat ileum contraction. Res Pharm Sci. 2015;10(5):446-52.

19. Sadraei H, Asghari G, Shahverdi F. Antidiarrhoeal assessment of hydroalcoholic and hexane extracts of Dracocephalum kotschyi Boiss. and apigenin in mice. Res Pharm Sci. 2016;11(3):200-9.

20. Sadraei H, Ghanadian M, Asghari G, Sekhavati N. Antispasmodic activity of apigenin and luteolin, two components of Dracocephalum kotschyi extract, on rat ileum 
contractions. J Herbmed Pharmacol. 2018;7(2):100-5. doi: 10.15171/jhp.2018.17.

21. Sadraei H, Asghari G, Alinejad M. Comparison of antispasmodic effect of hydroalcoholic extract of Dracocephalum kotschyi Boiss. in rat uterus and ileum. Res Pharm Sci. 2016;11(4):284-92. doi: 10.4103/17355362.189295.

22. Sadraei H, Ghanadian SM, Moazeni S. Inhibitory effect of hydroalcoholic and flavonoids extracts of Dracocephalum kotschyi, and its components luteolin, apigenin and apigenin4'-galactoside on intestinal transit in mice. J Herbmed Pharmacol. 2019;8(1):8-13. doi: 10.15171/jhp.2019.02.

23. Sadraei H, Ghanadian SM, Asghari G, Gavahian A. Bronchodilator effect of apigenin and luteolin, two components of Dracocephalum kotschyi on isolated rabbit trachea. J Herbmed Pharmacol. 2019;8(4):281-6. doi: 10.15171/jhp.2019.41.

24. Singh J. Maceration, percolation and infusion techniques for the extraction of medicinal and aromatic plants. Extraction technologies for medicinal and aromatic plants. Vol.67. Italy: Environmental and Marine Sciences and Technologies; 2008. p. 32-5.

25. Samuelsson G. Drugs of Natural Origin. Stockholm: Swedish Pharmaceutical Press; 1999. p. 48-9.

26. Ghasemi Dehkordi NA, Sajadi SE, Ghanadi AR, Amanzadeh Y, Azadbakht M, Asghari GH, et al. Iranian herbal pharmacopoeia (IHP). Hakim Research Journal. 2003;6(3):63-9. [Persian].

27. Harborn JB. Physiology and functions of flavonoids. In: Harborn JB, Mabary TJ, Mabary H, eds. The Flavonoids. Vol. 18. The United States: The University of Texas at Austin; 1975. p. 970-1055.

28. Blainski A, Lopes GC, de Mello JC. Application and analysis of the Folin Ciocalteu method for the determination of the total phenolic content from Limonium brasiliense L. Molecules. 2013;18(6):6852-65. doi: 10.3390/ molecules 18066852 .

29. Ferguson D, Christopher N. Urinary bladder function and drug development. Trends Pharmacol Sci. 1996;17(4):161-5. doi: 10.1016/0165-6147(96)81593-8.

30. Andersson KE, Arner A. Urinary bladder contraction and relaxation: physiology and pathophysiology. Physiol Rev. 2004;84(3):935-86. doi: 10.1152/physrev.00038.2003.

31. Andersson KE. Advances in the pharmacological control of the bladder. Exp Physiol. 1999;84(1):195-213. doi: 10.1111/j.1469-445x.1999.tb00083.x.

32. de Groat WC, Yoshimura N. Pharmacology of the lower urinary tract. Annu Rev Pharmacol Toxicol. 2001;41:691721. doi: 10.1146/annurev.pharmtox.41.1.691.

33. Andersson KE. Pathways for relaxation of detrusor smooth muscle. Adv Exp Med Biol. 1999;462:241-52. doi: 10.1007/978-1-4615-4737-2_18.

34. Deplanne V, Palea S, Angel I. The adrenergic, cholinergic and NANC nerve-mediated contractions of the female rabbit bladder neck and proximal, medial and distal urethra. Br J Pharmacol. 1998;123(8):1517-24. doi: 10.1038/ sj.bjp.0701757.

35. Elbadawi A. Pathology and pathophysiology of detrusor in incontinence. Urol Clin North Am. 1995;22(3):499-512.

36. Ji G, Barsotti RJ, Feldman ME, Kotlikoff MI. Stretchinduced calcium release in smooth muscle. J Gen Physiol. 2002;119(6):533-44. doi: 10.1085/jgp.20028514.
37. Burnstock G. Purinergic signalling in the urinary tract in health and disease. Purinergic Signal. 2014;10(1):103-55. doi: 10.1007/s11302-013-9395-y.

38. Herrera GM, Heppner TJ, Nelson MT. Regulation of urinary bladder smooth muscle contractions by ryanodine receptors and BK and SK channels. Am J Physiol Regul Integr Comp Physiol. 2000;279(1):R60-8. doi: 10.1152/ ajpregu.2000.279.1.R60.

39. Chess-Williams R. Muscarinic receptors of the urinary bladder: detrusor, urothelial and prejunctional. Auton Autacoid Pharmacol. 2002;22(3):133-45. doi: 10.1046/j.1474-8673.2002.00258.x.

40. Hegde SS, Eglen RM. Muscarinic receptor subtypes modulating smooth muscle contractility in the urinary bladder. Life Sci. 1999;64(6-7):419-28. doi: 10.1016/s00243205(98)00581-5.

41. Eglen RM, Hegde SS, Watson N. Muscarinic receptor subtypes and smooth muscle function. Pharmacol Rev. 1996;48(4):531-65.

42. Brading AF. The sarcoplasmic reticulum in disease and smooth muscle dysfunction: therapeutic potential. Novartis Found Symp. 2002;246:244-54. doi: 10.1002/0470853050. ch18.

43. Arner A, Pfitzer G. Regulation of cross-bridge cycling by $\mathrm{Ca}^{2+}$ in smooth muscle. Rev Physiol Biochem Pharmacol. 1999;134:63-146. doi: 10.1007/3-540-64753-8_3.

44. Horowitz A, Menice CB, Laporte R, Morgan KG. Mechanisms of smooth muscle contraction. Physiol Rev. 1996;76(4):967-1003. doi: 10.1152/physrev.1996.76.4.967.

45. Bolton TB, Prestwich SA, Zholos AV, Gordienko DV. Excitation-contraction coupling in gastrointestinal and other smooth muscles. Annu Rev Physiol. 1999;61:85-115. doi: 10.1146/annurev.physiol.61.1.85.

46. Ganitkevich V, Hasse V, Pfitzer G. Ca2+-dependent and $\mathrm{Ca}^{2+}$-independent regulation of smooth muscle contraction. J Muscle Res Cell Motil. 2002;23(1):47-52. doi: 10.1023/a:1019956529549.

47. Kotlikoff MI, Herrera G, Nelson MT. Calcium permeant ion channels in smooth muscle. Rev Physiol Biochem Pharmacol. 1999;134:147-99. doi: 10.1007/3-540-647538 8.

48. Katz AM. Pharmacology and mechanisms of action of calcium-channel blockers. J Clin Hypertens. 1986;2(3 Suppl):28S-37S.

49. Yono M, Yoshida M, Wada Y, Kikukawa H, Takahashi W, Inadome A, et al. Pharmacological effects of tolterodine on human isolated urinary bladder. Eur J Pharmacol. 1999;368(2-3):223-30. doi: 10.1016/s0014-2999(99)000369.

50. Chapple CR, Yamanishi T, Chess-Williams R. Muscarinic receptor subtypes and management of the overactive bladder. Urology. 2002;60(5 Suppl 1):82-8. doi: 10.1016/ s0090-4295(02)01803-4.

51. Creed KE, Ishikawa S, Ito Y. Electrical and mechanical activity recorded from rabbit urinary bladder in response to nerve stimulation. J Physiol. 1983;338:149-64. doi: 10.1113/ jphysiol.1983.sp014666.

52. Wu CH, Shieh TM, Wang KL, Huang TC, Hsia SM. Quercetin, a main flavonoid in onion, inhibits the PGF2alpha -induced uterine contraction in vitro and in vivo. J Funct Foods. 2015;19:495-504. doi: 10.1016/j.jff.2015.09.028. 